\title{
Mediastinal teratoma in a neonate with acute respiratory failure
}

\author{
Jarun Sayasathid ${ }^{\mathrm{a}}$, Naraporn Somboonna ${ }^{\mathrm{b}}$, Siraphop Thapmaogkol, Yuthapong Buddharadsa ${ }^{\mathrm{a}}$, \\ Kanchapan Sukonpan ${ }^{\mathrm{C}}$ \\ ${ }^{a}$ Cardiac Center, Naresuan University Hospital, Phitsanulok 65000; ${ }^{b}$ Department of Microbiology, \\ Faculty of Science, Chulalongkorn University, Bangkok 10330; 'Department of Obstetrics and \\ Gynecology, Buddhachinaraj Hospital, Phitsanulok 65000, Thailand
}

\begin{abstract}
Background: While teratomas account for the leading cause of germ cell tumors, the mediastinal teratomas represent one of the infrequent types of congenital germ cell tumors. Neonates with large mediastinal teratomas generally show severe respiratory distress, and the immediate surgical treatment is needed to alleviate their problems.

Objectives: Report clinical symptoms, diagnostic procedures, treatment option, and outcomes after the treatment for a neonate with a large mediastinal teratoma.

Methods: A 2-day-old female infant presented with acute respiratory failure diagnosed as mediastinal teratoma. It was followed with surgical treatment. The removed tissues were examined pathologically.

Results: The girl suffered an acute respiratory failure two days after birth. The chest radiography, echocardiography, and chest computerized tomography results showed the considerable size of the mediastinal teratoma. A median sternotomy was performed on the third day of infant life to remove the tumor without rupturing the capsule. Pathological diagnosis was germ cell tumor. Clinical follow-ups reported no complication.

Conclusion: The successful management of a neonate with large mediastinal teratomas was presented. Immediate detection and proper treatment of the large mediastinal teratoma in a neonate was most important to decrease the morbidity and mortality of the infant.
\end{abstract}

Keywords: Acute respiratory failure, germ cell tumor, mediastinal teratoma, median sternotomy, neonate

Among neonates, germ cell tumors represent the leading cause of abnormal proliferation of cells, known as a neoplasm. Among the different types of germ cell tumors, teratoma accounts for the most common histological type of germ cell tumors [1, 2]. Teratoma is an encapsulated tumor in which three germ layers are often identified. The three blastodermic layers, i.e. neuro-ectoderm, mesoderm, and endoderm, are the histological origins of teratomas developing into various organs, ranging from eye, torso, feet, brain, liver, and lung [3-6]. The origins of teratomas may also include cystic or solid areas with organoid patterns as mature or immature components [7].

Correspondence to: Jarun Sayasathid, MD, Cardiac Center, Naresuan University Hospital Phitsanulok 65000, Thailand. E-mail: jsayasathid@hotmail.com
Embryonic teratomas generally occur in the midline of the body, particularly in a sacrococcygeal area. The sacrococcygeal teratoma is the most common tumor found in newborns. In adults, due to the encapsulated morphology, most teratomas are benign. The benign teratomas are typically characterized by mature forms and are common in females, whereas the malignant teratomas are mostly found in immature forms and are common among males [6].

Unlike sacrococcygeal teratomas, the mediastinal teratomas are uncommon congenital germ cell tumors [8]. The incidence of mediastinal teratomas are approximately $20 \%$ of all mediastinal masses [9]. The fetal mediastinal teratomas comprise only $10 \%$ of all the congenital teratomas in children, and $7 \%$ of all the germ cell teratomas in childhood [10]. However, 
according to Kuroiwa et al. [11], only 17 alive newborns with mediastinal teratoma and acute severe respiratory distress have been reported to date. The small numbers of case reports emphasize the importance of more studies on mediastinal teratoma in newborn-infants. Further, many babies may present clinical symptoms relevant to their mediastinal teratoma later in life. In addition, some teratomas, especially the large size mediastinal teratoma, result in acute respiratory failure in neonatal period [10]. These explain the underestimation of babies with mediastinal teratoma. Consequently, surgical removal of the teratoma significantly improves the infant symptom, produces low recurrent rate, and thus, is proven as the only proper treatment of choice. Clinical complications after the surgery have been not reported yet. In this case-report, we described the first successful surgery of a mediastinal teratoma in a female neonate with acute respiratory failure in Thailand.

\section{Case report}

At Naresuan University Hospital, a female newborn-infant weighed 3,589 grams presented with acute respiratory failure, albeit the ultrasound check-ups detected no abnormal fetal structure during her antenatal period. The infant had progressive respiratory distress, and required intubation and ventilation support on the second day of life. Chest radiography showed a huge thoracic mass that occupied the left upper and middle lung fields, and her mediastinum shifted from the left to the right along with the tracheal displacement, as shown in Fig. 1.

An echocardiography was performed to eliminate a possibility of congenital heart disease. The result indicated the normal cardiac structure. A chest computerized tomography (CT) scan revealed the considerable size of inhomogeneous mass of calcification and fat density at the anterior mediastinum. The lump occupied nearly the entire left hemithorax of the infant (Fig. 2). Moreover, the measured alpha fetoprotein (AFP) and beta human choriomic gonadotropin (HCG) were extremely elevated. While the normal levels of AFP and HCG are $0-7.02 \mathrm{ng} / \mathrm{mL}$ and $0-1 \mathrm{mIU} / \mathrm{mL}$, the amounts of AFP and beta HCG in this infant at two days of life were $36,485 \mathrm{ng} / \mathrm{ml}$ (a 10,000-fold higher than the average AFP) and $12.45 \mathrm{mIU} / \mathrm{mL}$ (a 25-fold higher than the average beta HCG), respectively.

The median sternotomy was performed on the infant at the third day of life. A cardiopulmonary bypass was not used for this operative procedure. The total operation time was one hour, and the entire anterior mediastinal tumor was removed. Figure 3 displayed the intact immature encapsulated mass with solid and cystic components. The encapsulated cystic mass was $6.3 \mathrm{~cm}$. in width, by $5.8 \mathrm{~cm}$. in length, and by $4.8 \mathrm{~cm}$ in height.

The patient was extubated on her fourth day after the surgery. The pathological diagnosis of the removed intact encapsulated mass was grade 3 immature teratoma, containing neural, ectodermal, glandular, osseous, and cartilaginous tissues (Fig. 4). The baby recovered. She was discharged from the hospital two weeks following the operation. In addition, her AFP (59.38 ng/mL AFP) and beta HCG (0.174 mIU/mL) levels became within the normal range within two month post operation. The patient also reported no clinical complication, her growth and development was normal at the six months follow-up examination.

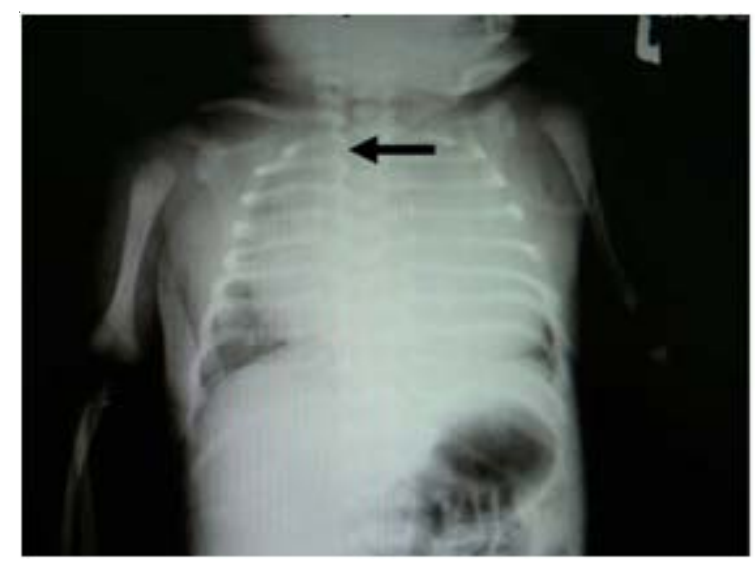

Fig. 1 Chest x-ray image showing a huge thoracic mass with mediastinum and tracheal displacement. Arrow indicates the location of the misplaced mediastinum and trachea. 

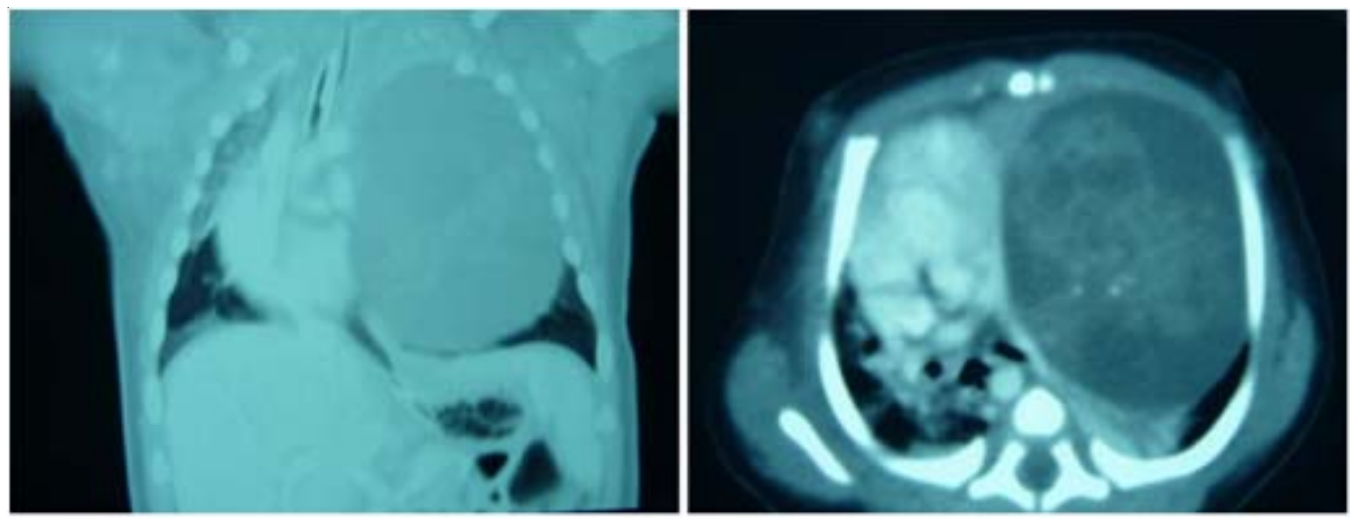

Fig. 2 Chest CT images demonstrating the large inhomogeneous mass at the anterior mediastinum. This occupied almost the entire left hemithorax.
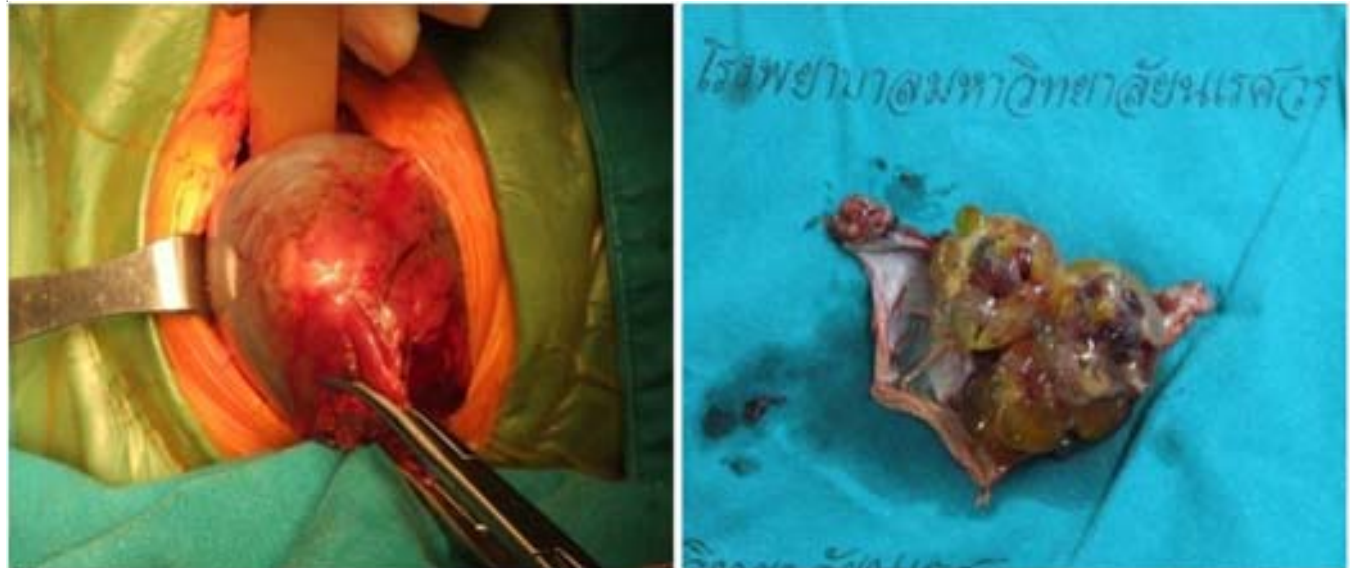

Fig. 3 The well-defined encapsulated mass with solid and cystic components.

A

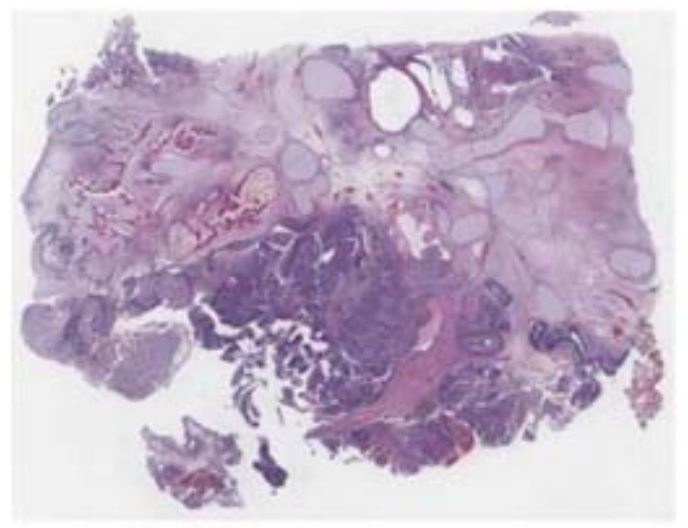

B

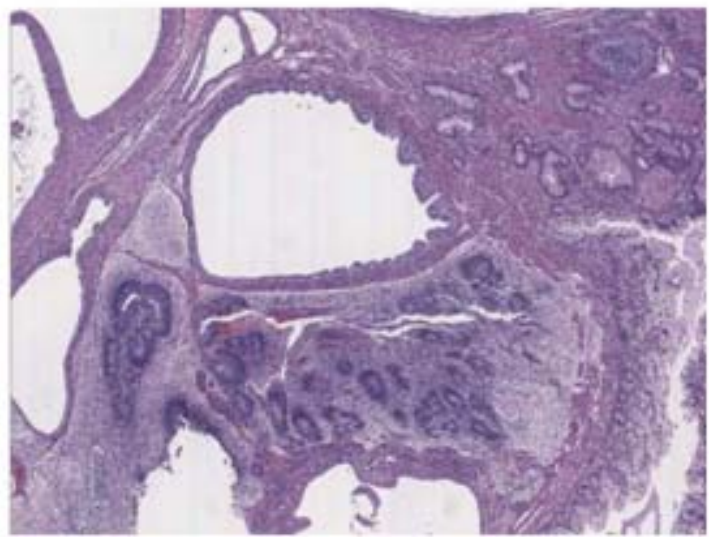

Fig. 4 Histology revealed various types of mature and immature tissues (A), as well as primitive neuroepithelial elements (B). 


\section{Discussion}

Although the occurrence of neonatal mediastinal teratomas is infrequent, cases of mediastinal teratomas have been reported for approximately $10 \%$ of the yearly congenital teratomas [10]. Most large teratomas result in severe respiratory distress owing to their extensive damage to the mediastinal structure in assorted respiratory areas, such as trachea, lung, and heart $[6,11]$. Further, this respiratory distress is rarely associated with pulmonary hypoplasia. The surgical removal of the tumors alleviates the respiratory problem.

The differential diagnosis mediastinal tumors include congenital cystic adenomatoid malformation, pulmonary sequestration, intrapericardial teratoma, and cardiac rhabdomyosarcoma [8]. The teratoma is suspected when the calcified mass is diagnosed using chest x-ray (see Fig. 1), ultrasound, CT (see Fig. 2), and/or magnetic resonance imaging (MRI). In addition, $\mathrm{CT}$ and MRI reveal information regarding the extent and positional association with the surrounding tissues. All are essential knowledge for the cardiac surgeons prior to surgery.

In neonates, the mediastinal teratomas are commonly found around the anterior and superior mediastinum. Importantly, many cases of congenital teratomas in the mediastinum are undetected unless the tumors have reached an extensive size [2]. A majority of the neonates with the mediastinal teratomas show abrupt respiratory distress when the tumors occupy a significant portion of the hemithorax, and emergency surgery in such the cases is essential. Hence, the time of operation is important. For infants who develop symptoms, the surgery should be performed once the teratomas are confirmed by qualified cardiac centers. Besides, for successful operation, preoperative hemodynamic and respiratory stabilization should be done for patients with coexisting pulmonary diseases. Moreover, the complete resection of the tumors is important to prevent local recurrences. Although thoracostomy may allow for the complete resection, the median sternotomy is adequate for general incision cases [7, 9, 11-16]. In addition, despite the nominal recurrent rate for congenital teratomas, the clinical and imaging investigative follow-ups are recommended [17]. The levels of AFP and beta HCG should also be obtained among a suspected neonate, and also for the teratoma-incised babies at pre- and post-operation periods $[18,19]$. Consistent with our reported high AFP and high beta HCG levels in the female infant with congenital mediastinal teratoma, Roy et al. [20] reported the elevated AFP level of up to $100,000 \mathrm{ng} / \mathrm{mL}$ at birth.

With routine prenatal ultrasound examination, fetal mediastinal teratomas may be diagnosed since a uterus stage. Meanwhile, despite advanced imaging techniques, some tumors could not be detected by routine ultrasound technique. This scenario is often found in mothers with fewer than twenty weeks of gestational age. The reason is because the sizes of their fetal tumors are likely too small to be distinguished during this examination time. In general, $80 \%$ of the prenatal diagnoses for the mediastinal tumors occur after twenty-three weeks of the gestational age [1]. The treatment varies, depending on the gestational period, the presence of hydrops and the risk of fetal compromise. A compromised fetus that shows a hydrops fetalis pattern and a large mediastinal teratoma before thirty weeks of gestation, can undergo an open fetal surgery in the uterus to remove the mediastinal mass. For the compromised fetus that is older than thirty weeks and has a mediastinal teratoma, the mediastinal mass resection should be performed after the delivery and the stabilization procedures, but if necessary, the mass may be resected while being on uteroplacental bypass with an uteroplacental bypass technique [8]. On the contrary, for the noncompromised fetus, regular surveillance procedures, including serial ultrasound, tumor size measurement, and deviated sign of hydrops and polyhydramnios, are recommended. Together, the prenatal diagnosis of the mediastinal tumor is always important for successful fetal delivery, prenatal management, and for the method of surgical operation. Coordinated teams of multi-disciplinary physicians and medical staffs are useful for punctual and proper disease diagnosis. This leads to the delivery of safe and healthy newborns, and the decreased morbidity and mortality for the neonates with teratomas.

In the present report, prenatal diagnosis for mediastinal tumor was not performed when the mother came for the ultrasound check-up at twenty weeks of gestation. Fortunately, the rapid and proper diagnosis by a qualified and well-coordinated health care team allowed the physician to manage the teratoma in this patient, bringing a satisfactory surgical treatment outcome.

In conclusion, large size mediastinal teratomas normally cause respiratory discomfort to the neonates. Effective diagnosis, prompt respiratory assistance, and 
therapy intervention for these newborns are key factors. With the complete tumor removal by median sternotomy, the surgical outcome is effective and shows no clinical complication.

\section{Acknowledgements}

We thank Assoc. Prof. Waneerat Galassi, Assist. Prof. Julintorn Somran, and Dr. Peerayut Sittichaiyakul for their information of the radiology and pathology. The authors have no conflict of interest to report.

\section{References}

1. Horton Z, Schlatter M,Schultz S. Pediatric germ cell tumors. Surg Oncol. 2007; 16: 205-13.

2. Soor GS, Chakrabarti MO, Luk A, Abraham JR, Phillips K, Butany J. Prenatal intrapericardial teratomas: diagnosis and management. Cardiovasc Pathol. 2008; 30:1-4.

3. Chi JG, Lee YS, Chang KY. Fetus-in-fetu: report of a case. Ame J Clin Pathol. 1984; 82:115-9.

4. Sergi C, Ehemann V, Beedgen B, Linderkamp O, Otto HF. Huge fetal sacrococcygeal teratoma with a completely formed eye and intratumoral DNA ploidy heterogeneity. Pediatr Dev Pathol. 1999; 2: 50-7.

5. Kuno N, Kadomatsu K, Nakamura M, Miwa-Fukuchi T, Hirabayashi J, Ishizuka T. Mature ovarian cystic teratoma with a highly differentiated homunculus: a case report. Birth Defects Res A Clin Mol Teratol. 2004; 70:40-6

6. Arlikar JD, Mane SB, Dhende NP, Sanghavi Y, Valand AG, Butale PR. Fetus in fetu: two case reports and review of literature. Pediatr Surg Int. 2009; 25:289-92.

7. Martino F, Avila LF, Encinas JL, Luis AL, Olivares $P$ Lassaletta L, et al. Teratomas of neck and mediastinum in children. Pediatr Surg Int. 2006; 22: 627-34.

8. Merchant AM, Hedrick HL, Johnson MP, Wilson RD, Crombleholme TM, Howell LJ, et al. Management of fetal mediastinal teratoma. J Pediatr Surg. 2005; 40: 228-31.
9. Seo T, Ando H, Watanabe Y, Harada T, Ito F, Kaneko $\mathrm{K}$, et al. Acute respiratory failure associated with intrathoracic masses in neonates. J Pediatr Surg. 1999; 34:1633-7.

10. Wilson RD. Management of fetal tumors. Best Pract Res Clin Obstet Gynaecol. 2008; 22: 159-73.

11. Kuroiwa M, Suzuki N, Takahashi A, Ikeda H, Hatakeyama SI, Matsuyama S, Matsuyama S, et al. Life-threatening mediastinal teratoma in a neonate. Pediatr Surg. 2001; 17: 235-8.

12. De Lorimier AA, Harrison MR. Surgical treatment of tumor in the newborn. Am J Pediatr Hematol Oncol. 1981; 3:271-7.

13. Mogilner JG, Fonseca J, Davies MR. Life-threatening respiratory distress caused by a mediastinal teratoma in a newborn. J pediatr Surg. 1992; 27:1519-20.

14. Wang KY, Yeh YC, Jean WH, Fan SZ. Cardiopulmonary resuscitation in the lateral position for an infant with an anterior mediastinal mass. Acta Anaesthesiol Taiwan. 2009; 47: 40-3.

15. Tollens T, Casselman F, Devlieger H, Gewillig MH, Vandenberghe K, Lerut TE, et al. Fetal cardiac tamponade due to an intrapericardial teratoma. Ann Thorac Surg. 1998; 66: 559-60.

16. Gobbi D, Rubino M, Chiandetti L, Zanon GF, Cecchetto G. Neonatal intrapericardial teratoma: a challenge for the pediatric surgeoun. J Pediatr Surg. 2007; 42: e3-6.

17. Isaacs H. Perinatal (fetal and neonatal) germ cell tumors. J Pediatr Surg 2004; 39(7): 1003-13.

18. Billmire DF. Germ cell tumors. Surg Clin N Am. 2006; 86: 489-503.

19. Gornall P. Paediatric Surgical oncology. Eur J Surg Oncol.1997; 23: 68-83.

20. Roy N, Blurton DJ, Azakie A, Karl TR. Immature intrapericardial teratoma in a newborn with elevated alpha-fetoprotein. Ann Thorac Surg. 2004; 78: e6-8.

21. Bell TA, Lightner DV. A Handbook of Normal Shrimp Histology. Baton Rouge:World Aquaculture Society, 1988. 